\title{
A CASE CONTROL STUDY OF INTRAVENOUS MAGNESIUM SULPHATE IN TREATMENT OF ACUTE ORGANOPHOSPHATE POISONING
}

\author{
James Philomena1, Vajaravelu Sathi², Parthasarathy Prathiba ${ }^{3}$
}

${ }^{1}$ Associate Professor, Department of General Medicine, Government Vellore Medical College and Hospital. ${ }^{2}$ Assistant Professor, Department of General Medicine, Government Vellore Medical College and Hospital. ${ }^{3}$ Post Graduate, Department of General Medicine, Government Vellore Medical College and Hospital.

\section{ABSTRACT}

\section{BACKGROUND}

To study the efficacy of intravenous magnesium sulphate in the treatment of OPC poisoning and its outcome. To assess merits and demerits of use of $\mathrm{MgSO} 4$ with conventional therapy.

\section{METHOD}

This is a case control study of patients admitted with severe OPC poisoning in intensive care medical unit of tertiary care hospital.

\section{RESULTS}

Total of 69 cases and 64 control patients were compared. Among both cases and controls incidence of poisoning was more common among male sex and common among patients belonging to third decade of age. When compared to control arm, there is statistically significant reduction in mortality when intravenous MgSO4 was given to patients in addition to standard treatme nt protocol for severe OPC poisoning.

\section{CONCLUSION}

In our study, addition of MgSO4 has shown significant clinical improvement of severe OPC poisoning with no adverse outcome. Long term and large studies are needed to determine the efficacy of MgSO4 in treatment of OPC poisoning.

\section{KEYWORDS}

Organophosphate Compound, Magnesium Sulphate, Peradeniya Organophosphorus Poisoning Scale.

HOW TO CITE THIS ARTICLE: Philomena J, Sathi V, Prathiba P. A case control study of intravenous magnesium sulphate in treatment of acute organophosphate poisoning. J. Evolution Med. Dent. Sci. 2016;5(38):2290-2294, DOI: $10.14260 /$ jemds/2016/532

\section{INTRODUCTION}

Organophosphate (OP) compounds have been employed as pesticides, petroleum additives and chemical warfare nerve agents. The organophosphates have been used as pesticides for more than 50 years and are still used in most developing countries. Organophosphate (OP) compounds have been widely used for a few decades in agriculture for crop protection and pest control; thousands of these compounds have been screened and over one hundred of them have been marketed for these purposes.(1) The common use of insecticides in public health and agricultural schedules has caused severe environmental pollution and potential health hazards including severe acute and chronic cases of human and animal poisoning.

OP compound poisoning is an important indication for emergency admission in most hospitals throughout India.(2) WHO estimates that approximately 3 million pesticide poisoning occur worldwide and cause more than 2,20,000 deaths. Developing countries like India and Srilanka report alarming rates of toxicity and death.

The potential adverse impact on human health from exposure to pesticides is likely to be higher in countries like

Financial or Other, Competing Interest: None.

Submission 15-04-2016, Peer Review 27-04-2016,

Acceptance 29-04-2016, Published 11-05-2016.

Corresponding Author:

Dr. Parthasarathy Prathiba,

No. 50, Andal Nagar,

Adukamparai, Vellore-632011

Tamilnadu.

E-mail: prathusarathy@gmail.com

DOI: $10.14260 /$ jemds/2016/532
India due to easy availability of highly hazardous products, and low risk awareness, especially among children and women. Overexposure to pesticides can occur before spraying- because of easy access for children, lack of adequate labelling and during mixing - during spraying and after spraying operations. Spray operators and bystanders can be affected. Having cheap and easily available, highly hazardous pesticides at hand increases the incidence of intentional pesticide poisonings. (3)

The commonly used OP insecticides are acephate, anilophos, chlorpyrifos, dichlorvos, diazinon, dimethoate, fenitrothion, methyl parathion, monocrotophos, phenthoate, phorate, pirimiphos, quinalphos, temephos, etc. Organophosphorus pesticides inhibit esterase enzymes, especially acetylcholinesterase in synapses and on red-cell membranes and butyrylcholinesterase in plasma.(4) Acetylcholinesterase inhibition results in accumulation of acetylcholine and overstimulation of acetylcholine receptors in synapses of the autonomic nervous system, CNS and neuromuscular junctions.

The recommended therapy for OP poisoning is the intravenous administration of atropine and pralidoxime. Atropine, a competitive inhibitor of acetylcholine counteracts the muscarinic effects of OP poisoning. It is used to reverse cholinergic effects of organophosphate poisoning like decreased heart rate, increased bronchial secretions, urination, lacrimation, etc. There are two approaches to atropinisation: 1. Bolus dose administration; 2. Incremental dose administration with rapid escalation. The goal of therapy is to prevent bradycardia, maintain blood pressure, 
clear lungs and dry skin. Atropine is associated with toxic effects like tachycardia, agitation and psychoses.

Glycopyrrolate has less CNS penetration and may result in less CNS toxicity. Pralidoxime is used to reactivate cholinesterase enzymes, but is ineffective once the enzyme has become irreversibly bound to organophosphate.(5)

Administration of magnesium to animals poisoned with Organophosphate Pesticides (OP) has been shown to improve outcome. The mechanism of action of magnesium remains elusive; it is considered to attenuate the toxicity of OP compounds by reducing acetylcholine release from presynaptic nerve terminal.(5) Magnesium sulphate blocks ligand-gated calcium channels, resulting in reduced acetylcholine release from pre-synaptic terminals, thus improving function at neuromuscular junctions and reduced CNS over-stimulation mediated via NMDA receptor activation. The administration of magnesium to animals poisoned with organophosphate pesticides improves outcome, possibly owing to a favourable effect on neuromuscular junction block or increased hydrolysis of some pesticides. $\left.{ }^{6}\right)$

\section{Need for the Study}

- To assess the usefulness of MgSO4 in acute OP poisoning in terms of mortality and morbidity.

- To find out the effect of Standard 4 gm dose of MgSO4 over 24 hours on mortality and morbidity of organophosphate poisoning.

- To assess merits and demerits of use of MgSO4 with conventional therapy.

\section{MATERIALS AND METHODS}

\section{Study Site}

This study was conducted in the patients admitted as organophosphate poisoning with severe toxicity in intensive medical care unit of Department of General Medicine, Vellore Medical College and Hospital.

\section{Study Design}

Case control study.

\section{Study Period}

Total duration was six months, October 2015 to March 2016.

\section{Study Criteria}

The patients admitted during October to December 2015 were taken as control and those admitted during January to March 2016 were taken as cases. Both cases and controlled were matched for age and sex and severity of OPC poisoning. Ethical Committee approval obtained. Patients admitted with definitive history of OPC poisoning in IMCU were classified according to the severity of poisoning based on Peradeniya Organophosphorus Poisoning Scale (POP).

\section{Inclusion Criteria}

- Patients admitted at IMCU, classified as severe poisoning by POP scale.

- Patients willing to take part in the study.

\section{Exclusion Criteria}

- Patients were excluded from the study if there was history or suspicion of ingestion of other drugs concomitantly.

- Patients with mild-to-moderate poisoning.
- Patient suffering from other comorbid illness like cardiac, pulmonary and renal insufficiency.

- Contraindications to MgSO4 therapy like heart block.

Immediately, after the arrival of the patients at the emergency department, history was taken to confirm the type of OP compound taken and the interval between the consumption of poison and arrival at the emergency was noted. Consent of the patient and relative was taken. Apart from the routine and detailed clinical examination, assessment was also done based on the Peradeniya Organophosphorus scaling system which included pupil size, respiratory rate, pulse rate, level of consciousness of the patient and the presence or absence of convulsion and fasciculation.

\begin{tabular}{|c|c|c|}
\hline Pupil Size & $>2 \mathrm{~mm}$ & 0 \\
\hline & $<2 \mathrm{~mm}$ & 1 \\
\hline & Pin point & 2 \\
\hline Respiratory Rate & $<20$ & 0 \\
\hline & $>20$ & 1 \\
\hline & $>20$ with central cyanosis & 2 \\
\hline Heart Rate & $>60$ & 0 \\
\hline & $41-60$ & 1 \\
\hline Fasciculation & $<40$ & 2 \\
\hline & None & 0 \\
\hline & Present, generalised or & 1 \\
\hline Level of & continuous & 1 \\
\hline Consciousness & Conscious and rational & 0 \\
\hline & $\begin{array}{c}\text { Impaired response to verbal } \\
\text { commands }\end{array}$ & 1 \\
\hline Seizure & No response to verbal commands & 2 \\
\hline Table 1: Peradeniya & Organophent & 0 \\
\hline & Present & 1 \\
\hline & \multicolumn{2}{|c|}{} \\
\hline
\end{tabular}

Based on this assessment, a score was given to the patients. A score of 0 to 3 is considered as mild poisoning, 4 to 7 as moderate poisoning and 8 to 11 as severe poisoning.

All patients will be decontaminated, treated with gastric lavage and standard treatment IV atropine and IV pralidoxime will be given as per guidelines. Atropine was started $1.8-3 \mathrm{mg}$ bolus, thereafter doubling the dose at 5 minutes interval until atropinisation was achieved and then continued as infusion, containing $10-20 \%$ of the total amount required for initial atropinisation and gradually reduced at a rate of $70-80 \%$ of the previous rate.(7) Target end-point for atropinisation was defined by clear chest on auscultation with no wheeze, heart rate 80 beats/min, pupils no longer pinpoint, dry axillae and systolic blood pressure 80 mmHg; 11 during atropinisation pulse, blood pressure, chest findings and pupil size were recorded every 5 minutes until atropinisation and then at least hourly thereafter. Pralidoxime was infused $(30 \mathrm{mg} / \mathrm{kg}$ over 60 minutes followed by $8 \mathrm{mg} / \mathrm{kg} / \mathrm{hr}$.).(7) until recovery or death. Supportive and intensive care therapies were decided by the attending physicians.

Consecutive patients will be administered with $4 \mathrm{~g}$ of IV magnesium sulphate infusion in $100 \mathrm{~mL}$ of NS over $1 \mathrm{hr}$. within the first 24 hours of admission. Patients were assessed for evidence of magnesium toxicity. Specifically, prior to the injection of MgSO4, the patient was examined for pulse, blood 
pressure, presence of deep tendon reflexes, respiration rate $16 /$ minute and urine output $100 \mathrm{~mL}$ since the preceding injection. In addition, $1 \mathrm{~g}$ of calcium gluconate was made available. The outcome of the patient and morbidity and mortality rates between the cases and control group were analysed. No adverse effect of IV MgSO4 has occurred among the cases.

\section{Data Analysis}

Data analysis and data entry were done using Statistical Package for Social Sciences (SPSS) software version 16. Comparison of outcome between cases and control group were carried by using Fisher test and two tailed $p$ value was calculated.

\section{RESULTS}

Total no. of cases included in the study according to inclusion criteria was 69 patients as cases and the control group had 64 patients.

\section{Age Distribution}

Both among cases and controls majority of the patients belonged to the age group 18 years to 30 years ( $48 \%$ of cases and $42 \%$ of controls).

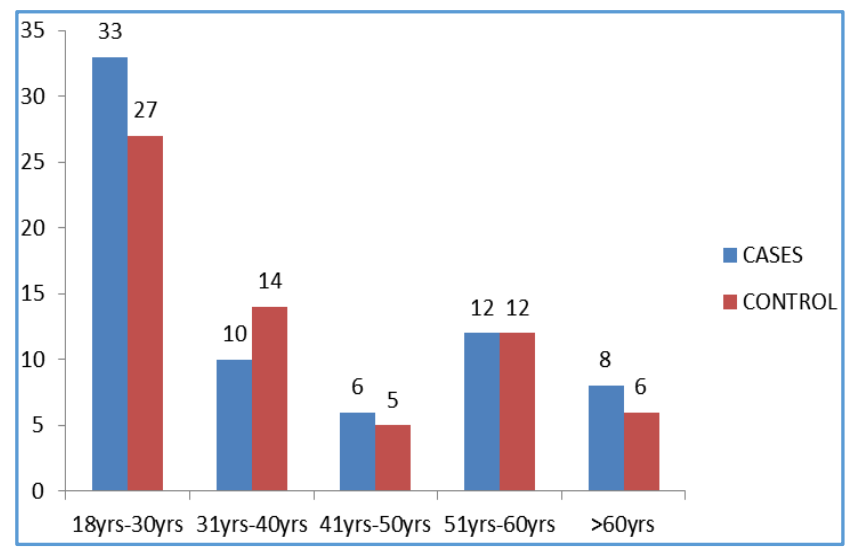

Fig. 1: Age Distribution

\section{Gender Distribution}

Both among cases and controls incidence of poisoning is more among male gender (Cases male $n=46$, controls male $\mathrm{n}=40$ ).

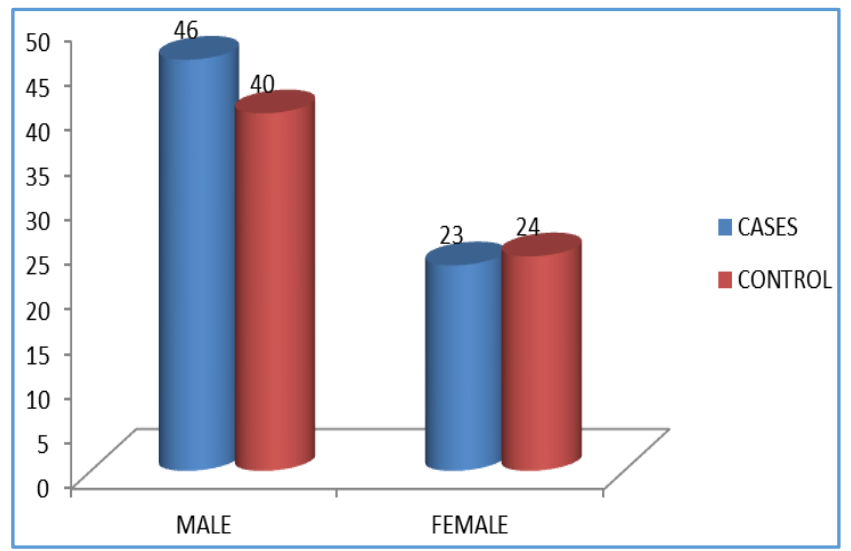

Fig. 2: Gender Distribution

\section{Outcome}

The cases and control group were compared for difference in the outcome. Among cases who were given intravenous MgSO4 within 24 hours of admission, 58 patients recovered and death was noted in 11 patients among cases. In the control group of those patients who received only the standard treatment for OPC poisoning, 44 patients recovered and 20 patients expired. The difference in the outcome among the cases and controls were statistically analysed using Fisher test and two tailed ' $\mathrm{p}$ ' value was obtained, $p=0.0421$, which showed statistical significance in difference in outcome among two groups.

Magnesium appeared to be well tolerated in all dosing strata. No immediate adverse effects of hypotension or diminished knee reflex were observed following magnesium sulphate administration. No patient received calcium gluconate.

\section{Time of Presentation to the Tertiary Care Centre}

Majority of the patients both among cases and control group who seeked medical attention to the tertiary care centre within the first 24 hours of consumption of poison recovered form toxicity.

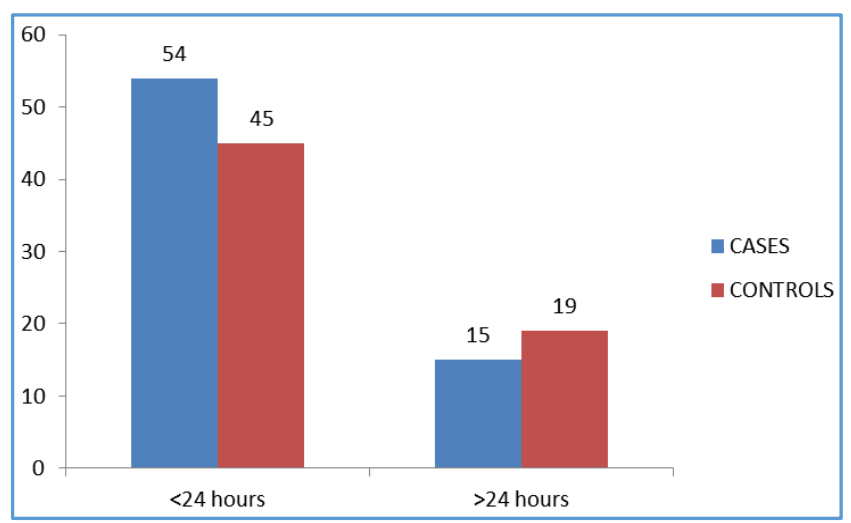

Fig. 3: Time of Presentation

\section{Need of Mechanical Ventilation}

Among the cases 23 patients developed respiratory failure and required mechanical ventilation, of which 12 patients recovered and 11 patients died. Among control group 30 patients who required mechanical ventilation, 10 recovered.

\section{DISCUSSION}

The causes of the high case fatality in OP poisoning are multifactorial and includes the high toxicity of locally available poisons, delayed presentation to hospital, the scarcity of health care professionals compared with the large numbers of patients, the lack of facilities including ICU care, antidotes and trained personnel for the management of pesticide-poisoned patients. ${ }^{8,9} 9$

In this study about $48 \%$ patients belonged to age group of 21-30, which was comparable to other studies.(10-12) In most of the studies.(10-14) incidence of poisoning was common among female, but in our study males were commonly affected. Basic steps involved in the treatment of poisoning are 1. Prevention of further absorption of the poison (Emesis, gastric lavage, chemical absorption, chemical inactivation, purgation); 2. Enhanced elimination of the poison (Biotransformation, biliary excretion, urinary excretion, 
dialysis); and 3. Antagonism and chemical inactivation of the absorbed drug.(15)

Inhibition and reactivation of acetylcholine esterase are largely dependent on the nature, relative concentration and the affinity of the OP compounds towards the enzyme. Variability of interaction causes ageing by depletion of one or more alkyl groups attached to the bound phosphate. While the use of atropine to antagonize muscarinic effects is standard care, the role of oximes is not well defined as efficacy or safety of oximes in these settings is not established. Oximes are relatively expensive and ineffective once acetylcholinesterase has aged. Thus alternative or adjunctive treatments that may alter acetylcholine release or protect the neuromuscular junction need to be explored.

Although, atropine and oximes (Pralidoxime or obidoxime) are traditionally used in the management of such poisoning, their efficacy remains a major issue of debate. Thus, the goal of this case control study was to elaborate the value of magnesium sulphate (MgSO4) in the management and outcome of OP insecticide poisoning.(16)

Magnesium inhibits acetylcholine release probably through blocking calcium channel. It has several attractive additional therapeutic properties including muscle relaxation, which could control spasms and cardiovascular effects (e.g. vasodilatation, lowering of heart rate and a reduction of systemic catecholamine release).(17,18)

In a unicenter, randomized, single-blind trial study was conducted on patients who were acutely poisoned with ops. Magnesium sulphate was administered at dose of $4 \mathrm{~g} /$ day IV, continued for only the first 24 hours after admission. The mortality rate and hospitalization days of patients who received $\mathrm{MgSO} 4$ treatment were significantly lower than those who had not received MgSO4 ( $\mathrm{P}<0.01)$. It is concluded that administration of $\mathrm{MgSO} 4$ in a dose of $4 \mathrm{~g}$ /day concurrent to conventional therapy in OP, acute human poisoning is beneficial by reducing the hospitalization days and rate of mortality.(19)

Similarly, in our study there was significant difference in outcome among cases and control. A similar small randomised study with $4 \mathrm{gm}$ magnesium in acute $\mathrm{OP}$ poisoning has been reported to decrease mortality. This study was very small; numerous parts of the methodology were incompletely described.(20)

A phase II trial was run in 4 sequential groups of patients. Six patients died in control group compared to 3 in 4 gm, 2 in 8 gm and 1 in 12 gm group. There was no mortality in 16 gm group. It was concluded that adverse effects could be attributed to intermittent bolus injections of magnesium doses (Up to 16 grams). Larger controlled studies should be performed to determine the efficacy of magnesium sulphate in OP poisoning.(21)

\section{LIMITATION}

Limitations of our study are small sample size and a further potential limitation is that we did not have the capacity to confirm exposure by analysis and identification of the specific organophosphate or by inhibition of cholinesterase. However, cohort studies in similar settings showed laboratory confirmation of agrochemicals ingestion in $95 \%$ of cases. ${ }^{22}$ ) Also delay in seeking medical attention and co-ingestion of other compounds and alcohol also influence the outcome.

\section{CONCLUSION}

In addition to the standard care of OPC poisoning, $\mathrm{MgSO} 4$ can be added in the management. In our study, addition of MgSO 4 has shown significant clinical improvement of severe OPC poisoning with no adverse outcome. Large controlled studies should be performed to determine the efficacy of magnesium sulphate in OP poisoning.

\section{REFERENCES}

1. Mogda K, Kashoury A, Rashed M. Nature and science. Dovepress 2009; $7^{\text {th }}$ ed.

2. Hardman JG, Limbird LE, Mulinoff PB, et al. Taylor $P$ anticholinesterase agents. In: goodman and gilman's the pharmacological basis of therapeutics $2006 ; 11^{\text {th }}$ ed:17682.

3. Health implications from monocrotophos use: a review of the evidence in India- WHO 2009;1-6.

4. Lotti M. Clinical toxicology of anticholinesterase agents in humans. In: Krieger R, ed. Handbook of pesticide toxicology. Agents san diego: academic press 2001;2:1043-85.

5. Buckley NA, Eddleston M, Li Y, et al. Oximes for acute organophosphate pesticide poisoning. Cochrane data base syst rev 2011;2:CD005085. doi:10.1002/14651858.

6. Peter B. Organo phosphorous poisoning- acute. Clinical Evidence 2010.

7. Eddleston M, Dawson A, Karalliedde L, et al. Early management after self-poisoning with an organophosphorus or carbamate pesticide- a treatment protocol for junior doctors. Crit Care 2004;8(6):391-7.

8. Eddleston M. Patterns and problems and deliberate selfpoisoning in the developing world. Q J Med 2000;93(6):715-31.

9. Buckley NA, Karalliedde L, Dawson A, et al. Where is the evidence for the management of pesticide poisoning- is clinical toxicology fiddling while the developing world burns? J Toxicol Clin Toxicol 2004;42(1):113-6.

10. Zawar SD. Correlation between plasma cholinesterase levels and clinical severity of acute organophosphate and carbamate poisoning. JAPI 2001;149:91.

11. Rehiman S, Lohani SP, Bhattarai MC. Correlation of serum cholinesterase level, clinical score at presentation and severity of OP poisoning. J Nepal Med Assoc 2008;47(170):47-52.

12. Arup KK. Predictors of mortality in organophosphorus poisoning-hospital based study from suburban West Bengal. JAPI 2011;49:91.

13. Tsao TC, Juang YC, Lan RS, et al. Respiratory failure of acute organophosphate and carbamate poisoning. CHEST 1990;98(3):631-6.

14. Nouira S, Abroug F, Elatrous S, et al. Prognostic value of serum cholinesterase in organophosphate poisoning. CHEST 1994;106(6):1811-4.

15. Brunton Laurence L. Principles of toxicology and treatment of poisoning. In: Klaassen Curtis D, editor. Goodman and gilman's the pharmacological basis of therapeutics. New York(NY): McGraw-Hill 2006;1156-9.

16. Eddleston M, Eyer P, Worek F, et al. Pralidoxime in acute organophosphorus insecticide poisoning- a randomised controlled trial. PLoS Med 2009;6:e1000104. 
17. Bradley RJ. Calcium or magnesium concentration affects the severity organophosphate-induced neuromuscular block. Eur J Pharmacol 1986;127(3):275-8.

18. Georg AP. Organophosphate poisoning: the lesserknown face of a toxidrome. Eur J Emerg Med 2005;12(2):102-3.

19. Pajoumand A, Shadnia S, Razaie A. Benefit of magnesium sulphate in the management of acute human poisoning by organophosphorus insecticides. Hum Exp Toxicol 2004;23(12):565-9.
20. Basher A, Rahman S, Ghose A. Pilot trial of OPC. Dhaka 2013.

21. Basher A, Rahman SH, Ghose A, et al. Phase II study of magnesium sulfate in acute organophosphate pesticide poisoning. Clinical Toxicology 2013;51(1):35-40.

22. Dawson AH, Eddleston M, Senarathna L, et al. Acute human lethal toxicity of agricultural pesticides: a prospective cohort study. PLoS Med 2010;7:e1000357. 